\title{
28 Research Square \\ Effects of Programmed Cell Death Induced by NO on Pollen Viability After Cryopreservation
}

\section{Ruifen Ren}

Beijing Forestry University

Hao Zhou

Beijing Forestry University

Lingling Zhang

Beijing Forestry University

Mengting Zhu

Beijing Forestry University

Xueru Jiang

Beijing Forestry University

Yan Liu ( $\square$ yanwopaper@yahoo.com )

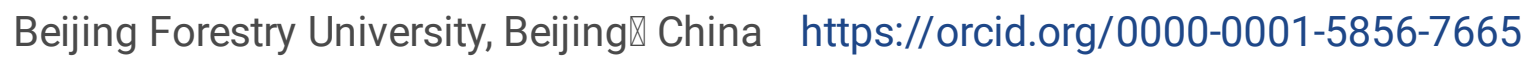

\section{Research Article}

Keywords: Germplasm conservation, Cryopreservation, Pollen, Nitric oxide, Programmed cell death, Viability

Posted Date: May 12th, 2021

DOI: https://doi.org/10.21203/rs.3.rs-511814/v1

License: (c) (1) This work is licensed under a Creative Commons Attribution 4.0 International License.

Read Full License 


\section{Abstract}

Low activity level of biomaterials after cryopreservation is a bottleneck problem that limited the application of this technology. At present, the mechanism of viability decline after cryopreservation is not fully understood. In this study, the effects of nitric oxide (NO) on programmed cell death (PCD) and its relationship with viability were investigated, using Paeonia lactiflora 'Fen Yu Nu' pollen with significantly decreased viability after cryopreservation. The results showed that: the activity of caspase-3-like and caspase-9-like protease and the apoptosis rate of pollen cells were significantly increased, the expression level of promoting PCD (pro-PCD) gene was up-regulated, while the expression level of inhibiting PCD (anti-PCD) gene was down-regulated after preserved in liquid nitrogen (LN); the NO content in pollen cells increased significantly after LN preserved. The results of correlation analysis showed that NO was significantly correlated with pollen viability and all indicators of PCD. The addition of NO carrier SNP after LN storage reduced pollen viability, increased endogenous NO content, decreased mitochondrial membrane potential level, activated caspase-3-like and caspase-9-like protease in pollen cells, and increased cell apoptosis rate, and the expression levels of pro-PCD genes PDCD2 and ATG8CL were significantly up-regulated, while the expression levels of anti-PCD genes $D A D 1, B I-1$ and $L S D 1$ were significantly down-regulated; and the addition of NO scavenger C-PTIO produced the opposite effect of SNP. It was suggested that NO induced the PCD during the cryopreservation of pollen, which was one of the reasons for the significant decrease of pollen viability after cryopreservation.

\section{Key Message}

After cryopreservation, the NO content increased, and caused the programmed cell death was one of the key reasons for the viability decreased.

\section{Introduction}

Cryopreservation is one of the important biotechniques for long-term, effective and safe preservation of plant germplasm resources, which can safely store biomaterials in $\mathrm{LN}\left(-196^{\circ} \mathrm{C}\right)$, and certain methods can be used to make them return to room temperature for normal growth and development when needed (Baust, 2002; Engelmann, 2004). Pollen, as an important carrier of plant germplasm resources, is one of the main forms of plant germplasm resources conservation. However, in the process of practical application, it has been found that pollen viability after cryopreservation have variety changes, but in most cases, the viability is at a declining level (Ren et al., 2019a), and the changes is probably due to the various stresses involved in the preservation process, such as osmotic and low temperature.

Nitric oxide (NO) is a kind of short-life free radicals of gaseous, which is produced in various stress response, and plays a role in a variety of physiological and biochemical processes, which mainly as a messenger and effector molecule (Delledonne, 2005; del Rio et al., 2006; Kasprowicz et al., 2009). Zhang found that low concentration of oligchitosan caused rapid and transient production of NO in suspension cells of Nicotiana tabacum (Zhang et al., 2012); He found that NO concentration increased significantly in 
the root tips of Arachis hypogaea under aluminum ion stress (He et al., 2017); Ye found the intracellular NO accumulation in Arabidopsis thaliana under cadmium ion stress (Ye et al., 2013). Similarly, it was also found that the NO content changed significantly after cryopreservation of plants. In the cryopreservation of Dendrobium nobile protocorms by vitrification, the accumulation of NO content in cells was accelerated by LN preservation (Jiang et al., 2019b).

Programmed cell death (PCD) is an active and orderly cell death controlled by genes (Kerr et al., 1972). Current studies have shown that, NO as a direct inducer of PCD response, is a major factor that determines whether the PCD occurrence or not (Mira et al., 2016), and it has been found that NO has a dual effect on the occurrence of stress-induced PCD in plants (Wang et al., 2010). Cadmium induced PCD in suspension cells of Nicotiana tobacillus (Ma et al., 2010) and aluminum induced PCD in root tip of Arachis hypogaea (He et al., 2017), NO is negatively involved in regulating the occurrence of PCD. On the contrary, NO plays a positive regulatory role in GA induced PCD in aleurone layer of barley (Beligni et al., 2002) and PCD of plant hypersensitivity induced by proenzyme (Zaninotto et al., 2006). Similarly, the double role of NO in PCD was also found in plant cryopreservation. Jiang found that in the vitrification cryopreservation of Dendrobium nobile protocorm, NO played a dual role in the occurrence of PCD, the content of NO increased significantly in the loading process, and it was negatively involved in the regulation of PCD; but in the pre-culture stage, although the content of NO increased significantly, it was positively involved in regulating the occurrence of PCD (Jiang,2019).

As an important method to preserve plant germplasm resources, existing studies have shown that there is a certain relationship between the changes of pollen viability and the occurrence of PCD after LN storage. In six P. suffruticosa cultivars, PCD was found to be involved in the changes of pollen viability after cryopreservation (Ren et al., 2020a). In the study of cryopreservation of $P$. lactiflora pollen, it was found that the exogenous additives catalase, pyruvate dehydrogenase and heat shock protein-70 had certain inhibitory effects on the activity of caspase-3-like protease and the apoptosis rate in PCD (Jiang et al., 2019a; Ren et al., 2019b). Further studies on cryopreservation of P. lactiflora 'Zi Feng Chao Yang' pollen showed that, ROS-induced PCD was one of the reasons for the significant decrease in pollen viability after LN preserved (Ren et al., 2020b). But, the role of NO in the occurrence of PCD in pollen cryopreservation has not been studied so far.

Therefore, in this study, the $P$. lactiflora lactiflora 'Fen Yu Nu' pollen with significantly decreased viability after cryopreservation as material. Investigated the changes of NO content, the occurrence of PCD, and the effects of exogenous NO regulator on pollen viability and PCD after cryopreservation, to explore the relationship between NO and PCD in pollen cryopreservation and the role of that in the decline of viability after cryopreservation.

\section{Materials And Methods}

\section{Pollen collection and cryopreservation}


The P. lactiflora lactiflora 'Fen Yu Nu' pollen were all collected from the Luoyang International Peony Garden (Luoyang, Henan Province, China) in April 29, 2019. When the dry and humidity of air is suitable, the flower buds that are about to open are selected, the anthers are gently picked and brought back under the $4^{\circ} \mathrm{C}$. Then, the anthers are naturally dried at room temperature $\left(23 \pm 2^{\circ} \mathrm{C}\right)$ for $24 \mathrm{~h}$. The pollen is completely dispersed, and the pollen is collected with an $80 \mathrm{~mm}$ aperture sieve (Ren et al., 2019a).

Divide the collected pollen $(0.1 \mathrm{~g} /$ package) into tin foil, place it in a $2 \mathrm{~mL}$ cryopreserved tube, and then directly put it into LN for storage. When needed, the pollen were frozen with running water (Ren et al., 2019a).

\section{Determination of pollen moisture content and viability}

Pollen moisture content was determined by $105^{\circ} \mathrm{C}$ constant temperature drying method, the detailed procedure are shown in the existing studies (Ren et al., 2019a).

Pollen germination level was detected by suspension drop method, the culture medium contained $10 \%$ sucrose and $0.1 \%$ boric acid. Take $15 \mu \mathrm{L}$ pollen culture medium on the cover glass, add trace amount of pollen and mix well. Turn the cover glass over immediately and place it in a glass groove (with $20 \mu \mathrm{L}$ pollen culture medium). The culture was placed in the dark at $25^{\circ} \mathrm{C}$ in a humid environment for $4 \mathrm{~h}$, the length of pollen tube was greater than twice the diameter of pollen grains as the criterion for pollen germination. Four replicates were set for each treatment, and three fields were randomly selected for each replicate. The germination number was counted with a 20X eyepiece (Leica DM-500), and the mean value of the results (Ren et al., 2019a).

\section{Determination of pollen NO content}

The content of NO was determined by DAF-FM DA fluorescence staining (Biyuntian Biotechnology Co., Ltd., S0019). Added $200 \mu \mathrm{L}$ DAF-FM DA (100 $\mu \mathrm{mol} / \mathrm{L})$ into $0.01 \mathrm{~g}$ pollen, thoroughly mixed. Incubated at $37^{\circ} \mathrm{C}$ for 30 min without light, centrifuged at $2000 \mathrm{rmp}$ for $20 \mathrm{~s}$, discarded the dye solution. Washed twice with $500 \mu \mathrm{L}$ PBS $(\mathrm{pH}=7.4)$, then diluted the precipitated pollen with $1 \mathrm{~mL}$ PBS $(\mathrm{pH}=7.4)$. Fluorescence value was measured at FITC channel by flow cytometer (FACSCalibur, Becton-Dickinson, Franklin Lakes, NJ, USA), the without adding fluorescent dye as control. The relative content of NO was taken as the actual fluorescence measurement value, and each treatment was repeated 3 times.

\section{Determination of pollen mitochondrial membrane potential}

Pollen mitochondrial membrane potential was detected by JC-1 fluorescence staining. $0.01 \mathrm{~g}$ pollen was added to $300 \mu \mathrm{L}$ paraformaldehyde (4\%), fixed at room temperature for $5 \mathrm{~min}$, discarded the paraformaldehyde, $300 \mu \mathrm{L}$ immunostaining permeable solution Triton X-100 (Biyuntian Biotechnology Co., Ltd., P0096) was added, permeable treatment at room temperature for 5 min. $500 \mu \mathrm{L}$ PBS(pH=7.4) was used to wash the permeable pollen cells for twice. 
$0.5 \mathrm{~mL}$ of JC-1 staining solution (Biyuntian Biotechnology Co., Ltd., C2006) was added to the precipitated pollen, thoroughly mixed, incubated at $37^{\circ} \mathrm{C}$ for 30 min without light. Fluorescent staining solution was removed and $500 \mu \mathrm{L} J \mathrm{C}-1$ staining buffer $(1 \mathrm{X})$ was added to wash the stained pollen for twice, then $1 \mathrm{~mL}$ $\mathrm{JC}-1$ staining buffer (1X) was added to resuspend the fluorescent loaded pollen. Fluorescence was detected by flow cytometry (BD-FACSAriaSORP, Becton-Dickinson, Franklin Lakes, NJ, USA). The negative control was the pollen without fluorescence loading, and the red-green fluorescence ratio was taken as the result. Each treatment repeated for 3 times.

\section{Determination of pollen caspase-like protease activity}

Caspase-3-like and caspase-9-like protease activities were detected using the kit provided by Biyuntian Biotechnology Co., Ltd (C1116, C1158). $0.03 \mathrm{~g}$ pollen was homogenized with $300 \mu \mathrm{L}$ lysate at $4^{\circ} \mathrm{C}$, then cracked the homogenate in ice bath for $5 \mathrm{~min}$, and centrifuged at $12000 \mathrm{rmp}$ at $4{ }^{\circ} \mathrm{C}$ for $20 \mathrm{~min}$. Added 50 $\mu \mathrm{L}$ supernatant extract into $40 \mu \mathrm{L}$ detection buffer solution, and $10 \mu \mathrm{L}$ caspase-3-like protease reaction substrate Ac-DEVD-pNA ( $2 \mathrm{mM})$ or caspase-9-like protease reaction substrate Ac-LEHD-pNA (2mM) was added to initiate the reaction, incubated in the dark at $37^{\circ} \mathrm{C}$ for $2 \mathrm{~h}$. The absorbance was measured at the wavelength of $405 \mathrm{~nm}$, the lysate as the control. Each treatment was repeated 3 times, and the average of the results was taken.

\section{Determination of pollen cells apoptosis rate}

Apoptosis rate was detected by Annexin V-FITC and PI double staining. $0.01 \mathrm{~g}$ pollen was fixed and transparent treated as mitochondrial membrane potential determination, then added $200 \mu \mathrm{L}$ cell staining buffer and $10 \mu \mathrm{L}$ Annexin V-FITC staining solution, incubated in darkness at $4^{\circ} \mathrm{C}$ for $30 \mathrm{~min}$, after Annexin V-FITC staining, $15 \mu \mathrm{L} \mathrm{PI} \mathrm{was} \mathrm{added} \mathrm{in} \mathrm{the} \mathrm{dark} \mathrm{for} \mathrm{staining}(15 \mathrm{~min})$. Removed the staining solution and $500 \mu \mathrm{L} P B S \llbracket \mathrm{pH}=7.4 \rrbracket$ was added to wash the stained pollen for twice, $600 \mu \mathrm{L} P B S \unrhd \mathrm{pH}=7.4 \rrbracket$ was added to resuspend the fluorescent loaded pollen. Pollen suspensions were used as control without any staining and separately stained by Annexin V-FITC or PI, fluorescence value was determined by flow cytometry (BD-FACSAriaSORP, Becton-Dickinson, Franklin Lakes, NJ,USA), and each treatment was repeated for 3 times.

\section{qRT- PCR analysis of pollen PCD-related genes}

Approximately $0.05 \mathrm{~g}$ pollen were ground into powder by LN. Total RNA was extracted using the Plant RNA Rapid Extraction Kit (RN38-EasySpin Plus) provided by Beijing Aidlab Biotechnologies Co., Ltd., and the procedure are detailed in the instructions. The CDNA was synthesized using the Rever Tra Ace ${ }^{\circledR}$ qPCR RT Master Mix with gDNA Remover kit (TOYOBO, Osaka, Japan), and the procedure according to the manufacturer's instructions. The primers were designed using IDT online software (https://sg.idtdna.com/Primerquest/Home/Index) and synthesized by Beijing Ruiboxingke Biological Technology Co., Ltd (Tab. 1). 
Real-time quantitative PCR according to the instructions of SYBR Premix EX Taq (Takara, Otsu, Japan) on the MiniOpticon ${ }^{\text {TM }}$ Real-time PCR Detection System (Bio-Rad ${ }^{\circledR}$, Hercules,CA). The amplification protocols for qRT-PCR included an initial denaturing step $\left(95^{\circ} \mathrm{C}\right.$ for $\left.30 \mathrm{~s}\right)$, followed by 40 cycles of $95^{\circ} \mathrm{C}$ for $10 \mathrm{~s}$, $\mathrm{T}_{\mathrm{m}}\left({ }^{\circ} \mathrm{C}\right)$ for $15 \mathrm{~s}$, and $72^{\circ} \mathrm{C}$ for $15 \mathrm{~s}, 65^{\circ} \mathrm{C}$ for $5 \mathrm{~s}$ and $95^{\circ} \mathrm{C}$ for $5 \mathrm{~s}$ (Wan et al., 2019). The reaction system was $20 \mu \mathrm{L}$, including $1 \mu \mathrm{L}$ cDNA, $2 \mu \mathrm{L}$ forward primer $(10 \mu \mathrm{M}), 2 \mu \mathrm{L}$ reverse primer $(10 \mu \mathrm{M}), 5 \mu \mathrm{L} \mathrm{ddH}_{2} \mathrm{O}$, and $10 \mu \mathrm{L} \mathrm{SYBR}{ }^{\circledR}$ Premix Ex Taq II (Tli RNaseH Plus) (2X). The expression level of the target gene was calculated by the $2^{-\Delta \Delta \mathrm{Cq}}$ method, and each treatment was repeated 3 times.

\section{Addition of NO exogenous regulator}

Different concentrations of NO carrier SNP (228710-5G, Sigma Chemical Co., St Louis, MO, USA) or NO scavenger c-PTIO (C221-10MG, Sigma Chemical Co., St Louis, MO, USA) solutions were added to the LN preserved pollen without thaw treatment at a ratio of 1:100 (w/v), mixed and incubated at $37^{\circ} \mathrm{C}$ for 10 min in the dark. Centrifuged at $2000 \mathrm{rpm}$ for $30 \mathrm{~s}$ to remove the regulator solution, then PBS $\llbracket \mathrm{pH}=7.4 \llbracket$ was added to wash the pollen for 3 times. The precipitated pollen was used for the determination of various indexes, and 3 replicates for each sample.

\section{Statistical analysis}

Flow data was analyzed with FlowJo software. SPSS 17.0 (Version 17.0 SPSS Inc., Chicago, IL, USA) was used for one-way ANOVA analysis and correlation analysis. Microsoft Excel 2013 software (Microsoft Corp., Richmond, CA, USA) and Origin 2019b (Origin Lab, Northampton, Massachusetts, USA) for chart and table drawing.

\section{Results}

\section{Moisture content and viability changes of pollen after cryopreservation}

The natural moisture content of fresh pollen was $8.10 \%$, and the viability of it was $22.73 \%$. The cryopreservation process significantly reduced the pollen viability $(P<0.05)$, especially the viability of pollen without water thawing treatment after $L N$ storage, which was only 16.42 , significantly lower than that of the fresh pollen (Tab. 2).

\section{The occurrence of PCD in pollen during cryopreservation}

As a fluorescent indicator of mitochondrial membrane potential, $\mathrm{JC}-1$ is often used to indicate the change level of membrane potential by its presence form in mitochondrial matrix. The number of pollen JC-1 transformed from polymer to monomer after $L N$ preservation was significantly increased (Fig. 1- A2, A3), thus the ratio of monomer to polymer was significantly decreased $(P<0.05)$, respectively decreased by $55.76 \%$ and $54.85 \%$ compared with the control (Fig. 1- B). The results showed that cryopreservation significantly reduced the mitochondrial membrane potential level of P. lactiflora 'Fen Yu Nu' pollen. 
Cryopreservation had a significant effect on the activity of pollen caspase-like protease. The activity of caspase-3-like protease in pollen without and with thawing treatment after $\mathrm{LN}$ storaged was significantly higher than that of control $(P<0.05)$, which was increased by $12.35 \%$ and $5.67 \%$, respectively (Fig. $2-A)$, moreover, the activity of caspase-9-like protease also increased significantly after $L N$ storaged $(P<0.05)$, which respectively increased by $26.89 \%$ and $12.30 \%$ compared with the fresh pollen (Fig. 2-B).

Cryopreservation significantly affected the apoptosis rate of pollen cells (Fig. 3). The apoptotic rate of pollen cells increased significantly after LN preservation (Fig. 3-B, C, D), especially without thawing treatment after preserved in $L N(L N)$, the apoptosis rate of pollen cells was relatively high (Fig. 3- B, D).

The expression levels of PCD related genes were significantly changed before and after cryopreservation. The expression of pro-PCD genes $P D C D 4, P D C D 2, A T G 8 C L$ and $A C D 11$ were significantly up-regulated in the pollen without thawing treatment after preserved in $L N$, while the expression of pro-PCD genes $S B T 3$, RTNLB2, AMC9, BAG6 was significantly up-regulated in pollen without and with thawing treatments after LN preservation (Fig. 4), the expression of anti-PCD genes $D A D I, B I-1$ and $L S D 1$ was significantly downregulated in the pollen after preserved in LN (Fig. 4).

\section{The changes of NO content in pollen during cryopreservation}

Cryopreservation has a significant effect on NO content in pollen (Fig. 5). The NO content of pollen without and with thawing treatment after $\mathrm{LN}$ storage were all significantly higher than that of the control level $(P<0.05)$, increased by $94.14 \%$ and $92.71 \%$, respectively(Fig. 5-D).

\section{Correlation analysis of pollen viability, PCD indexes and NO content in cryopreservation}

There was a certain correlation among NO content, PCD indexes and viability of pollen before and after cryopreservation (Fig. 6). Pollen viability was negatively correlated with caspase-3-like protease activity, caspase-9-like protease activity and apoptosis rate $(P<0.01)$, and positively correlated with the mitochondrial membrane potential $(P<0.05)$.

The content of NO was positively correlated with the apoptosis rate, the activity of caspase-3-like and caspase-9-like protease $(P<0.01)$, and negatively correlated with the mitochondrial membrane potential $(P<0.01)$, while, there was a significantly negative correlation between NO and viability in pollen cryopreservation $(P<0.05)$.

\section{Effects of regulating NO on pollen viability after cryopreservation}

The addition of different concentrations of exogenous NO regulators after LN storage had outstanding effects on pollen viability (Fig. 7). Added $0.6 \mathrm{mM}$ and $0.8 \mathrm{mM}$ NO carrier SNP significantly inhibited pollen viability after $L N$ storaged, especially $0.6 \mathrm{mM}$ SNP had a remarkable inhibitory effect on pollen viability (Fig. 7-A), while, No scavenger c-PTIO at $0.4 \mathrm{mM}, 0.6 \mathrm{mM}$ and $0.8 \mathrm{mM}$ significantly promoted pollen viability after $\mathrm{LN}$ storaged, and the optimization effect of $0.8 \mathrm{mM}$ c-PTIO on pollen viability was the most obvious (Fig. 7-B). 


\section{Effects of regulating NO on pollen endogenous NO content after cryopreservation}

The addition of exogenous NO regulators had a certain effect on the endogenous NO content of pollen after LN storage (Fig. 8). After LN storaged, added the SNP of NO carrier significantly increased the endogenous NO content, especially the SNP at $0.8 \mathrm{mM}$, which increased by $31.05 \%$ compared with the control (Fig. 8-A). While, the addition of different concentrations of NO scavenger C-PTIO significantly reduced the endogenous NO content, and the $0.6 \mathrm{mM}$ c-PTIO decreased by $32.92 \%$, which showed the most obvious inhibition effect (Fig. 8-B).

\section{Effects of regulating NO on the occurrence of PCD of pollen after cryopreservation}

The regulation of NO content had an effect on mitochondrial membrane potential of pollen after cryopreservation (Fig. 9). The addition of NO carrier SNP of appropriate concentration ( $0.8 \mathrm{mM})$ after LN storaged significantly reduced the ratio of $\mathrm{JC}-1$ polymers to monomers, that is, accelerated the decrease of mitochondrial membrane potential level (Fig. 9- A3, B), but the addition of C-PTIO of appropriate concentration $(0.8 \mathrm{mM})$ after cryopreserved did't have significant effect on the ratio of pollen JC-1 polymers to monomers (Fig. 9- A2, B).

The addition of NO regulators significantly affected the activities of caspase-3-like and caspase-9-like proteases (Fig. 10). After LN preservation, the appropriate concentration ( $0.8 \mathrm{mM})$ of SNP not only improved the activity of caspase-3-like protease, but also significantly enhance the activity of caspase-9like protease. However, the addition of appropriate concentration $(0.8 \mathrm{mM})$ of c-PTIO significantly inhibited the activity of caspase-3-like and caspase-9-like proteases (Fig. 10 - A, B).

The apoptosis rate of pollen cells was significantly affected by the regulation of NO content (Fig. 11). After preservation of $L N$, the addition of NO carrier SNP at an appropriate concentration $(0.8 \mathrm{mM})$ increased the apoptosis rate of pollen cells (Fig. 11- C, D), while the NO scavenging agent C-PTIO at $0.8 \mathrm{mM}$ significantly decreased the apoptosis rate of pollen cells (Fig. 11-B, D).

Exogenous NO regulator also significantly affected the expression of some PCD-related genes (Fig. 12). The addition of NO carrier SNP significantly up-regulated the expression levels of pro-PCD genes $P D C D 2$, $A T G 8 C L, A C D 11$ and $A M C 9$, down-regulated the expression levels of anti-PCD genes $D A D I, B I-1, H X K 1$, $\angle S D 1$ and pro-PCD genes $P D C D 4, B A G 6$, and RTNLB2 after preserved in $L N$. The addition of NO scavenger C-PTIO significantly down-regulated the expression levels of PDCD4, PDCD2, SBT3, ATG8CL, ACD11, BAG6 and RTNLB2 of pro-PCD genes, and significantly up-regulated the expression of $D A D I, B I-1$ and $L S D 1$, which inhibited the occurrence of PCD.

\section{Discussion}

In this study, the viability of $P$. lactiflora 'Fen Yu Nu' pollen decreased significantly after cryopreservation whether they were treated with or without water thawing. This is consistent with the results of a large number of studies. Xu found that the viability of 26 species/cultivars of ornamental plant pollen 
decreased significantly after cryopreserved 1 year (Xu et al., 2014); Mortazavi found that the viability of pollen of three cultivars of Phoenix dactylifera decreased after cryopreservation (Mortazavi et al., 2010); Ren found that after cryopreservation of 102 species/ cultivars of ornamental plant pollen for 8 years, the viability level of most species/ cultivars showed a significant decline (Ren et al., 2020a).

PCD is a gene-controlled, active and orderly process of cell death, as a normal physiological response of an organism in the environment and its own metabolism, which can be induced under a variety of stresses (Kerr et al., 1972). Studies have shown that low temperature and osmotic stress involved in cryopreservation induced PCD in plant materials. Jiang in the cryopreservation of Dendrobium nobile protocorms and Ren in the Paeonia suffruticosa pollen cryopreservation found that the activity of caspase-3-like protease and cell apoptosis rate were increased to a certain extent, and some PCD regulatory genes were significantly changed, indicated that cryopreservation induced PCD (Jiang et al., 2019b;Ren et al., 2020a). In this study, after cryoppreservation, pollen mitochondrial membrane potential significantly decreased, the activities of caspase-3-like and caspase-9-like protease and the apoptosis rate of pollen cells significantly increased, the expression levels of pro-PCD genes RTNLB2, AMC9 and $B A G 6$ were significantly up-regulated, and the expression of anti-PCD genes $D A D I, B I-1$ and $L S D 1$ were significantly down-regulated. The results showed that PCD also occurred in the cryopreservation of pollen of $P$. lactiflora 'Fen Yu Nu'.

Studies have shown that the occurrence of PCD affected the change of viability of biomaterials after cryopreservation. Zhang found that the changes of PCD-related genes in vitrification cryopreservation were related to the changes of cell viability in the cryopreservation of embryogenic callus of Agapanthus praecox (Zhang et al., 2015); and in the cryopreservation of Dendrobium nobile protocorms, Jiang found that the activity of caspase-3-like protease increased, which indicated PCD occurred, and that some proPCD genes were significantly up-regulated during the viability significantly decreased periods (Jiang et al., 2019b); Ren found that the occurrence of PCD was related to the changes of pollen viability in the cryopreservation of 6 cultivars of Paeonia suffruticosa (Ren et al., 2020a). This study is consistent with these findings. During the cryopreservation, pollen viability was negatively correlated with caspase-3-like protease activity, caspase-9-like protease activity and apoptosis rate, and positively correlated with the mitochondrial membrane potential, all these indicators are involved in the occurrence of PCD. The results indicated that PCD contributed to the decrease of pollen viability after cryopreservation in P. lactiflora 'Fen Yu Nu'.

Nitric oxide (NO) is a short-lived gaseous free radicals. In this study, the NO content of $P$. lactiflora 'Fen Yu $\mathrm{Nu}$ ' pollen increased significantly after LN storage. These results are consistent with the results of cryopreservation of Dendrobium nobile protocorms by vitrification (Jiang et al., 2019b). This suggested that the increase of endogenous NO content after cryopreservation may be a common phenomenon in preserved of plant materials.

The binding of NO with cysteine mercaptan of protein to form s-nitrosolation is an important posttranslational modification, which is considered to be an important pathway for $\mathrm{NO}$ to regulated cellular 
redox signaling. In recent years, a large number of proteins in plants have been identified as the targets of s-nitrosoylation, especially in the process of PCD, which directly affected the occurrence of PCD mainly by regulating the activity of cell death related enzymes or by reconstructing the conformation of several functional proteins, either positively or negatively involved in the PCD (Huang et al., 2019). In suspension cells of Arabidopsis thaliana under cadmium stress, NO is a key forward regulator of PCD (De Michele et al., 2009); as a signal component of 6-BA-induced PCD in suspension cells of Arabidopsis thaliana, NO positively regulated PCD (Carimi et al., 2005). In contrast, exogenous NO inhibited PCD in Arachis hypogaea root tip induced by aluminum stress, while NO-specific scavengers accelerated the occurrence of PCD, in which NO played a negative regulatory role (He et al., 2017); in the aleurone layer of Hordeum vulgare, NO delayed the occurrence of PCD and played a negative regulatory role (Beligni et al., 2002). However, some studies have shown that NO is not related to the occurrence of PCD. Da Silva found that NO production in suspension cells of Nicotiana tobacillus was not necessary for PCD induced by hydrospingosine (Da Silva et al., 2011). It can be seen that NO has multiple effects on PCD in plants, which may mainly depend on various factors, such as cell types, cellular redox status, local NO flux and dose and the like (Wang et al., 2010).

Correlation analysis results of this study showed that the NO content of pollen before and after LN storaged was positively correlated with the activities of caspase-3-like protease, caspase-9-like protease and cell apoptosis rate, while negatively correlated with mitochondrial membrane potential; and significantly negative correlation with pollen viability. In addition, in this study, added appropriate concentration of NO-specific scavenger c-PTIO decreased the content of endogenous NO, inhibited the PCD indexes of pollen, including the activities of caspase-3-like protease, caspase-9-like protease and the apoptosis rate, and improved the viability of pollen; while the addition of NO carrier SNP significantly reduced the mitochondrial membrane, promoted the activation of caspase-3-like and caspase-9-like protease as well as the generation of apoptosis rate, and significantly reduced the pollen viability. This is consistent with the results of Jiang in the vitrification cryopreservation of Dendrobium nobile protocorms, the addition of NO-specific scavenger (c-PTIO) in the pre-culture process can significantly reduced the activity of caspase-3-like protease; while the addition of NO carrier SNP in the pre-culture process significantly promoted the activation of caspase-3-like protease; and also the c-PTIO and SNP had different effects on the cell activity after LN preservation (Jiang et al., 2019b; Jiang, 2019). The results indicated that NO was positively involved in the regulation of PCD in the cryopreservation of pollen, thus influencing the viability of pollen after preservation with LN.

Previous studies have shown that $P D C D$ gene involved in the regulation of PCD by binding with histone acetyltransferase, translocated the pro-apoptotic factor Bax from cytoplasm to mitochondria, then participated the regulation of PCD (Chen et al., 2001; Chen at al., 2006). As a Bax homologous gene, Bl-1 (Bax-inhibitor 1) gene as an anti-PCD gene located in the endoplasmic reticulum, by interacted with $B a x$ to determine the occurrence of early PCD in cells under cold stimulation (Kawei-Yamada et al., 2001;Zhao et al., 2014). By catalyzing n-chain glycosylation, DAD1 gene interacted with $M c l-1$, an anti-apoptotic protein of $B C l-2$ family, then participated the regulation of PCD (Makishima et al., 2000). In this study, the appropriate concentration of NO specific scavenger c-PTIO added after preserved in LN significantly 
down-regulated the expression of pro-PCD gene $P D C D 2$, and significantly up-regulated the expression of anti-PCD gene $D A D 1$ and $B I-1$; while the addition of NO carrier SNP significantly up-regulated the expression of pro-PCD gene PDCD2, and decreased the expression of anti-PCD gene DAD1 and BI-1. Among them, $B I-1$ is the related regulation gene of endoplasmic reticulum pathway $P C D$, and $P D C D 2$ is the key regulation gene of mitochondrial pathway PCD. These results indicated that NO was not only involved in the regulation of endoplasmic reticulum pathway PCD, but also involved in the mitochondrial pathway PCD. However, the specific mechanism of its effect is still not fully answered in this study and further study is needed.

In this study, the NO scavenger c-PTIO significantly up-regulated the expression of LSD1 gene, while the NO carrier SNP significantly down-regulated its expression. $L S D 1$ protein encodes a negative regulatory gene for plant PCD, which contains three zinc fingers, antagonizes the accumulation of copper and zinc superoxide dismutase, and control the cell death by maintaining the homeostasis of reactive oxygen species (ROS) intermediates (Dietrich et al., 1997; Epple at al., 2003). These results suggest that NO may participated the regulation of PCD by acting on ROS during pollen cryopreservation. As in the process of root tip PCD induced by aluminum stress in Arachis hypogaea, NO regulates PCD by acting on $\mathrm{H}_{2} \mathrm{O}_{2}(\mathrm{He}$ et al., 2019); In the vitrification cryopreservation of Dendrobium nobile protocorms, NO was also found to be involved in PCD by positively regulating ROS (Jiang et al., 2019b).

In addition, in this study, the NO-specific scavenger c-PTIO significantly down-regulated the expression of pro-PCD gene ATG8CL; the SNP of NO carrier has the opposite effect. As a gene family involved in autophagy, ATG8CL participated the occurrence of autophagy by acting on the microtubule skeleton to mediate the formation of autophagosomes, or acting on mitochondrial membrane proteins (Broda et al., 2018). However, existing studies have shown that it also plays an important role in the process of PCD (Shibuya et al., 2011). In the cryopreservation of Dendrobium nobile protocorms by vitrification, Jiang also found that NO regulator had a significant effect on the expression of ATG8CL gene (Jiang,2019). It may be that NO plays a certain role in the occurrence of PCD by participated the regulation of autophagosome formation during cryopreservation of pollen, but the specific mechanism of effect needs to be further explored.

\section{Conclusion}

This study first investigated the role of NO in the occurrence of PCD during cryopreservation of pollen and the relationship with pollen viability. It was found that NO-induced PCD played an important role in the decline of pollen viability after cryopreservation. The pollen viability of $P$. lactiflora 'Fen Yu Nu' decreased after LN preservation, and PCD occurred, accompanied by significant increase of intracellular NO content; the production of NO was significantly correlated with the occurrence of PCD and the decline of pollen viability; and regulation of NO content regulated PCD-related cellular, physiological and gene expression, then affected the pollen viability.

\section{Declarations}


Acknowledgements: This research was supported by the National Natural Science Foundation of China (No. 31370693 and No. 31770741). And we thank Jiao Pengcheng and Ji Jiaojiao (Core Facility, Center of Biomedical Analysis, Tsinghua University) for technical support with flow cytometry analysis.

Conflict of interest: The authors declare that they have no conflict of interest.

Author contribution statement: Ruifen Ren designed the research, completed the experiment\analyzed the data and drafted the manuscript. Hao Zhou, and Mengting Zhu offered some help on the material collection. Lingling Zhang offered some help on the technical of the experiment. Xueru Jiang offered some help on the research designed. Yan Liu conceived the project, supervised the analysis and critically revised the manuscript. All authors read and approved the manuscript.

\section{References}

1. Baust JM, Buskirk RV, Baust JG (2002) Gene activation of the apoptotic caspase cascade following cryogenic storage. Cell Preservation Technology 1: 63-80.

2. Beligni MV, Fath A, Bethke PC, Lamattina L, Jones RL (2002) Nitric oxide acts as an antioxidant and delays programmed cell death in barley aleurone layers. Plant Physiology 129(4): 1642-1650.

3. Broda M, Millar AH, Van Aken O (2018) Mitophagy: A mechanism for plant growth and survival. Trends in Plant Science 23(5): 434-450.

4. Carimi F, Zottini M, Costa A, Cattelan I, De Michele R, Terzi M, Lo Schiavo F (2005) NO signalling in cytokinin-induced programmed cell death. Plant Cell and Environment 28(9): 1171-1178.

5. Chen YY, Sun RH, Han WL (2001) Nuclear translocation of PDCD5 (TFAR19): An early signal for apoptosis. FEBS Letters 509: 191-196.

6. Chen LN, Wang Y, Chen YY (2006) Short interfering RNA against the PDCD5 attenuates cell apoptosis and caspase-3 activity induced by Bax overexpression. Apoptosis 11:101-11.

7. Da Silva D, Lachaud C, Cotelle V, Brière C, Grat S, Mazars C, Thuleau P (2011) Nitric oxide production is not required for dihydrosphingosine-induced cell death in tobacco BY-2 cells. Plant Signaling \& Behavior 6(5):736-739.

8. Delledonne M (2005) NO news is good news for plants. Current Opinion in Plant Biology 8: 390-396.

9. De Michele R, Vurro E, Rigo C, Costa A, Elviri L, Di Valentin M, Careri M, Zottini M, di Toppi L S, Lo Schiavo $F$ (2009) Nitric oxide is involved in cadmium-induced programmed cell death in Arabidopsis suspension cultures. Plant Physiology 150, 217-228.

10. del Rio LA, Sandalio LM, Corpas FJ, Palma JM, Barroso JB (2006) Reactive oxygen species and reactive nitrogen species in peroxisomes. Production, scavenging, and role in cell signaling. Plant Physiology 141: 330-335.

11. Dietrich RA, Richberg MH, Schmidt R, Dean C, Dangl JL (1997) A novel zinc finger protein is encoded by style of debase the Arabidopsis $L S D 1$ gene and functions as a negative regulator of plant cell death. Cell 88: 685-694. 
12. Engelmann F (2004) Plant cryopreservation: progress and prospects. In Vitro Cellular \& Developmental Biology. Plant 40(5):427-433.

13. Epple P, Mack AA, Morris VR, Dan J L (2003) Antagonistic control of oxidative stress-induced cell death in Arabidopsis by two related, plant-specific zinc finger proteins. Proceedings of the National Academy of Sciences 100(11): 6831-6836.

14. He HY, Huang WJ, Oo TL, Gu MH, He LF (2017) Nitric oxide inhibits aluminum induced programmed cell death in peanut (Arachis hypoganea) root tips. J Hazard Mater 333: 285-292.

15. He HY, Oo T L, Huang WJ, He LF, Gu MH (2019) Nitric oxide acts as an antioxidant and inhibits programmed cell death induced by aluminum in the root tips of peanut (Arachis hypogaea). Scientific Reports 9: 9516.

16. Huang DJ, Huo JQ, Zhang J, Wang CL, Wang B, Fang H, Liao WB (2019) Protein S-nitrosylation in programmed cell death in plants. Cellular and Molecular Life Sciences 76:1877-1887.

17. Jiang XR, Ren RF, Di W, Jia MX, Li ZD, Liu Y, Gao RF (2019b) Hydrogen peroxide and nitric oxide are involved in programmed cell death induced by cryopreservation in Dendrobium protocorm-like bodies. Plant Cell, Tissue and Organ Culture (PCTOC) 137:553-563.

18. Jiang XR, Di W, Jia MX, Li ZD, Ren RF, Xu J, Li BL, Liu Y (2019a) MDH and CAT increase the germination of cryopreserved Paeonia pollen by regulating the ROS and apoptosis-like events. Acta Horticulturae 1234: 105-112.

19. Jiang XR (2019) Study on the mechanism of programmed cell death during vitrificationcryopreservation in Dendrobium protocorm-like bodies. Beijing Forestry University (in Chinese).

20. Kawei-Yamada M, Jin L, Yoshinaga K, Hirata A, Uchimiya H (2001) Mammalian Bax-induced plant cell death can be down-regulated by overexpression ofArabidopsis Bax inhibitor-I (AtBI-1). Proceedings of the National Academy of Sciences of the United States of America 98: 12295-12300.

21. Kasprowicz A, Szuba A, Volkmann D, Baluska F, Wojtaszek P (2009) Nitric oxide modulates dynamic actin cytoskeleton and vesicle trafficking in a cell type-specific manner in root apices. Journal of Experimental Botany 60:1605-1617.

22. Kerr JF, Wyllie AH, Currie AR (1972) Apoptosis: a basic biological phenomenon with wide-ranging implications in tissue kinetics. British Journal of Cancer 26(4): 239-257.

23. Makishima T, Yoshimi M, Komiyama S, Hara N, Nishimoto T (2000) A subunit of the mammalian oligosaccharyltransferase, DAD1, interacts with Mcl-1, one of the bcl-2 protein family. Journal of biochemistry 128(3): 399-405.

24. Ma W, Xu W, Xu H, Chen Y, He Z, Ma M (2010) Nitric oxide modulates cadmium influx during cadmium-induced programmed cell death in tobacco BY-2 cells. Planta 232(2): 325-335.

25. Mira M, Hill RD, Stasolla C (2016) Regulation of programmed cell death by phytoglobins. Journal of Experimental Botany 67(20):5901-5908.

26. Mortazavi SMH, Arzani K, Moieni A (2010) Optimizing storage and in vitro germination of date palm (Phoenix dactylifera) pollen. Journal of Agricultural Science and Technology 12(2): 181-189. 
27. Ren RF, Li ZD, Li BL, Xu J, Jiang XR, Liu Y, Zhang KY (2019a) Changes of pollen viability of ornamental plants after long-term preservation in a cryopreservation pollen bank. Cryobiology 89:1420.

28. Ren RF, Jiang XR, Di W, Li ZD, Li BL, Xu J, Liu Y (2019b) HSP70 improves the viability of cryopreserved Paeonia lactiflora pollen by regulating oxidative stress and apoptosis-like programmed cell death events. Plant Cell, Tissue and Organ Culture (PCTOC) 139:53-64.

29. Ren RF, Li ZD, Zhou H, Zhang LL, Jiang XR, Liu Y (2020a) Changes in apoptosis-like programmed cell death and viability during the cryopreservation of pollen from Paeonia suffruticosa. Plant Cell. Tissue Organ Cult (PCTOC) 140:357-368.

30. Ren RF, Li ZD, Jiang XR, Liu Y (2020b) The ROS-associated programmed cell death causes the decline of pollen viability recovered from cryopreservation in Paeonia lactiflora. Plant Cell Reports, 39:941-952.

31. Shibuya K, Shimizu K, Yamada T, Ichimura K (2011) Expression of autophagy-associated ATG8 genes during petal senescence in Japanese morning glory. Journal of the Japanese Society for Horticultural Science 80(1): 89-95.

32. Wang YQ, Chen C, Loake GJ, Chu CC (2010) Nitric oxide: promoter or suppressor of programmed cell death? [J]. Protein Cell 1(2): 133-142.

33. Wan YL, Hong AY, Zhang YX, Liu Y (2019) Selection and validation of reference genes of Paeonia lactiflora in growth development and light stress. Physiol Mol Biol Plants, 25(4):1097-1105.

34. Xu J, Li BL, Liu Q, Shi Y, Peng JG, Jia MX, Liu Y (2014) Wide-scale pollen banking of ornamental plants through cryopreservation, Cryoletters 35:312-319.

35. Ye Y, Li Z, Xing D (2013) Nitric oxide promotes MPK6-mediated caspase-3-like activation in cadmiuminduced Arabidopsis thaliana programmed cell death. Plant Cell Environ 36, 1-15.

36. Zhang HY, Wang WX, Yin H, Zhao XM, Du YG (2012) Oligochitosan induces programmed cell death in tobacco suspension cells. Carbohydrate Polymers 87:2270-2278.

37. Zaninotto F, La Camera S, Polverari A, Delledonne M (2006) Cross talk between reactive nitrogen and oxygen species during the hypersensitive disease resistance response. Plant Physiol 141(2):379-383

38. Zhang D, Ren L, Chen GQ, Zhang J, Reed BM, Shen XH (2015) ROS-induced oxidative stress and apoptosis-like event directly affect the cell viability of cryopreserved embryogenic callus inAgapanthus praecox. Plant Cell Reports 34(9):1499-1513.

39. Zhao YY, Chen JX, Tao XY, Zheng XJ, Mao LC (2014) The possible role of BAX and BI-1 genes in chilling-induced cell death in cucumber fruit. Acta Physiologiae Plantarum 36:1345-1351.

\section{Tables}

Tab. 1 The primer sequence of PCD target gene and the appropriate qRT-PCR annealing temperature 


\begin{tabular}{|c|c|c|c|}
\hline Gene & Full names of gene & Primer sequences $\left[5^{\prime}-3^{\prime} \square\right.$ & $\mathrm{T}_{\mathrm{m}} /{ }^{\circ} \mathrm{C}$ \\
\hline \multirow[t]{2}{*}{ PDCD4 } & \multirow[t]{2}{*}{ Programmed cell death protein 4} & F:CTTCCCTTTGATCGTCCGTTAG & \multirow[t]{2}{*}{58.3} \\
\hline & & R:CAACTCCAGTGTCGGATTTAGG & \\
\hline \multirow[t]{2}{*}{$P D C D 2$} & \multirow{2}{*}{$\begin{array}{l}\text { Programmed cell death protein } 2 \\
\text { isoform } \mathrm{X} 1\end{array}$} & F:CGACCACCACCACAATAACT & \multirow[t]{2}{*}{58.3} \\
\hline & & R:GTAGGAATGAGAGAGCCAAACC & \\
\hline \multirow[t]{2}{*}{ SBT3 } & \multirow{2}{*}{$\begin{array}{l}\text { Subtilisin-like protease SBT3.17 } \\
\text { isoform X2 }\end{array}$} & F:CTTAGCCGAGAAACCACTCG & \multirow[t]{2}{*}{58.3} \\
\hline & & R:CAAAACGAGGAGCCTGAATC & \\
\hline \multirow[t]{2}{*}{$A C D 11$} & \multirow[t]{2}{*}{ Accelerated cell death 11-like } & F:GAGACAGATTACGTCGCTAAGG & \multirow[t]{2}{*}{59.4} \\
\hline & & R:CCTCACACGTTTCCCTTGTA & \\
\hline \multirow[t]{2}{*}{$B I-1$} & \multirow[t]{2}{*}{ Bax inhibitor 1} & F:GTTCCAGAGGATATGCAGGTAAG & \multirow[t]{2}{*}{59.4} \\
\hline & & R:CCCATCTCAAGCAGGTCTATTT & \\
\hline \multirow[t]{2}{*}{$D A D 1$} & \multirow{2}{*}{$\begin{array}{l}\text { Dolichyl-diphosphooligosaccharide- } \\
\text { protein glycosyltransferase subunit } \\
\text { DAD1 }\end{array}$} & F:TTCTCCAATCACTCCGTTCTG & \multirow[t]{2}{*}{59.4} \\
\hline & & R:GACCCAACGATAGCCATGTA & \\
\hline \multirow[t]{2}{*}{ ATG8CL } & \multirow{2}{*}{$\begin{array}{l}\text { Autophagy-related protein } 8 \mathrm{C} \text {-like } \\
\text { isoform } \mathrm{X} 1\end{array}$} & F:AGTGCCGAGAAAGCCATATTTA & \multirow[t]{2}{*}{58.3} \\
\hline & & R:AGCCATCTTCATCCTTGTTCTC & \\
\hline \multirow[t]{2}{*}{$B A G 6$} & \multirow[t]{2}{*}{ BAG domain-containing protein } & F:GGCGTGGAAATAGAACACAAAG & \multirow[t]{2}{*}{59.4} \\
\hline & & R:GTTCAGCTCTTCCCTCCATAAA & \\
\hline \multirow[t]{2}{*}{$\angle S D 1$} & \multirow[t]{2}{*}{ Protein LSD1 } & F:GCCCAACGCTTCTCTAATCT & \multirow[t]{2}{*}{58.3} \\
\hline & & R:AGAATGCTCCTACACCCATTAC & \\
\hline \multirow[t]{2}{*}{$R T N L B 2$} & \multirow[t]{2}{*}{ Reticulon-like protein B3 } & F:CCAGAGTGAGCAAGTGGTATT & \multirow[t]{2}{*}{59.4} \\
\hline & & R:CATCTTCCTGTGGAGAGACAAG & \\
\hline \multirow[t]{2}{*}{$H \times K 1$} & \multirow[t]{2}{*}{ Hexokinase-1 } & F:CCAGTACCCAAGATAACGGAAG & \multirow[t]{2}{*}{58.3} \\
\hline & & R:GGAAAGGCAAGGCCTAGATATG & \\
\hline \multirow[t]{2}{*}{ AMC9 } & Metacaspase-9-like & F:AGAGTTGTTCGGAAGCGATG & 59.4 \\
\hline & & R:AGCTTGGCATCCACTCAATAG & \\
\hline GAPDH & Glyceraldehyde-3-phosphate & F:GGGCTGAATTCGTTGTTGAG & 58.3 \\
\hline $\begin{array}{l}\text { (Reference } \\
\text { gene) }\end{array}$ & & R:CTTGGGGCTGAGATGATGAC & \\
\hline
\end{tabular}

Tab. 2 Moisture content and germination percentage of $P$. lactiflora pollen 


\begin{tabular}{|lllll|}
\hline Cultivar & Moisture content / \% & \multicolumn{3}{l|}{ Germination percentage / \% } \\
\cline { 3 - 5 } & & Fresh(CK) & LN & Thaw \\
\hline P. lactiflora 'Fen Yu Nu' & $8.10 \pm 0.59$ & $22.73 \pm 1.64 \mathrm{a}$ & $16.42 \pm 0.82 \mathrm{c}$ & $20.80 \pm 2.27 \mathrm{~b}$ \\
\hline
\end{tabular}

Notes: Values of moisture content represent the mean ( \pm SE) over 3 detections; values of germination percentage represent the mean ( \pm SE) over 12 detections. Different letters indicate significant differences among different treatments at the 0.05 level $(P<0.05$, Duncan's multiple range test).

\section{Figures}
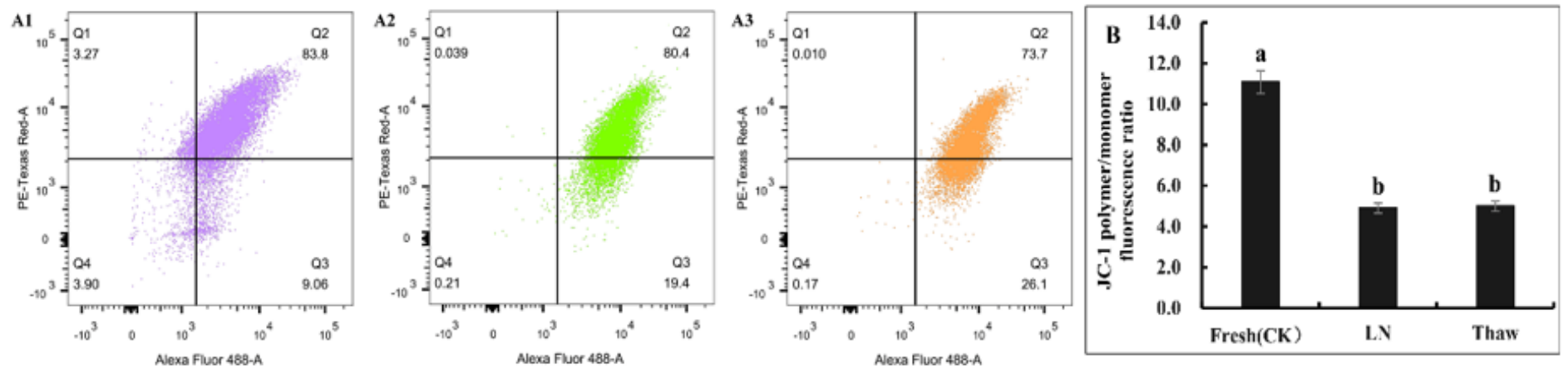

\section{Figure 1}

Changes of mitochondrial membrane potential in P. lactiflora pollen before and after cryopreservation. Notes: Values represent the mean $( \pm \mathrm{SE})$ over 3 detections. Different letters indicate significant differences among different treatments $(P<0.05)$. A1: control (fresh pollen/CK); A2 $\$ the LN preserved pollen without thaw treatment $(L N)$; $A 3 \otimes t$ the $L N$ preserved pollen with thaw treatment (Thaw); $B$ : the changes of JC-1 monomer and polymer ratio of pollen.
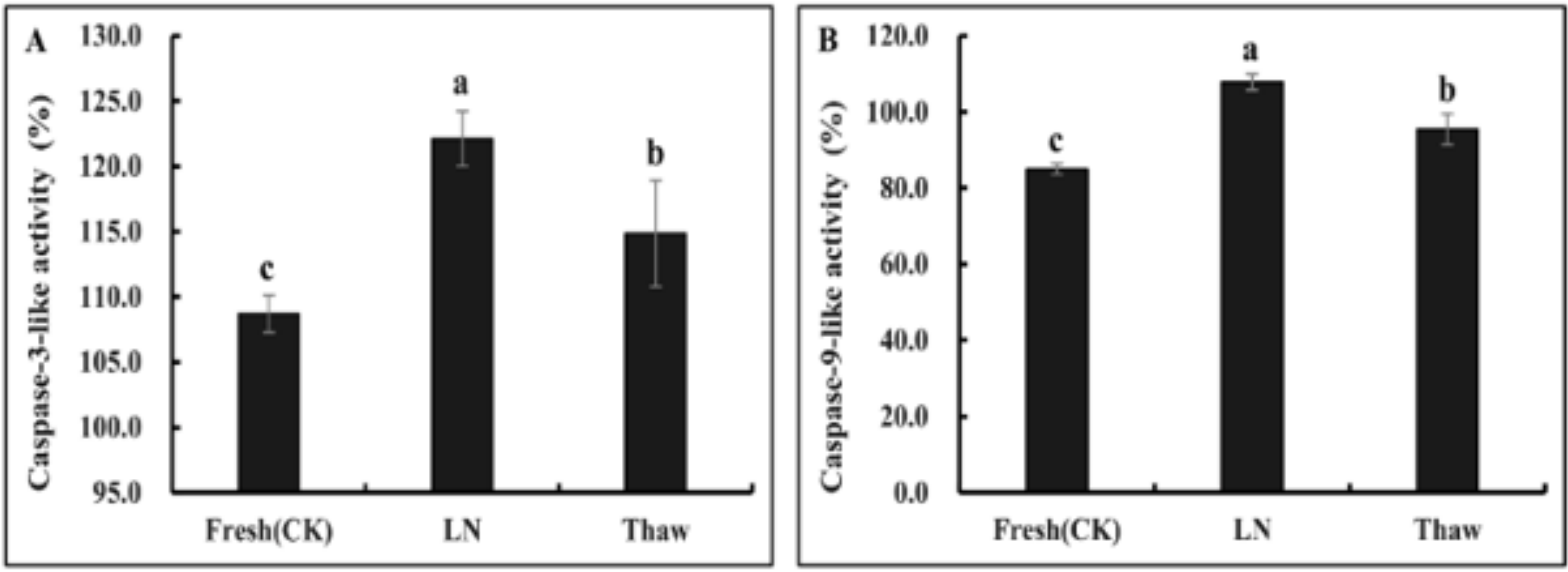

Figure 2 
Changes of caspase-like protease activity in P. lactiflora pollen before and after cryopreservation. Notes: Values represent the mean $( \pm S E)$ over 3 detections. Different letters indicate significant differences among different treatments $(P<0.05)$. CK: control (fresh pollen); LN囚the LN preserved pollen without thaw treatment; Thaw $₫$ the $L N$ preserved pollen with thaw treatment. A: caspase-3-like protease activity; B: caspase-9-like protease activity.
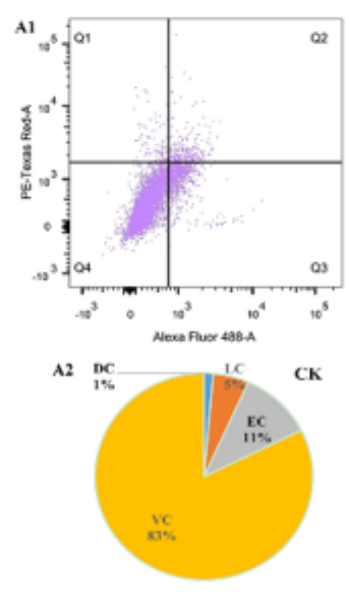

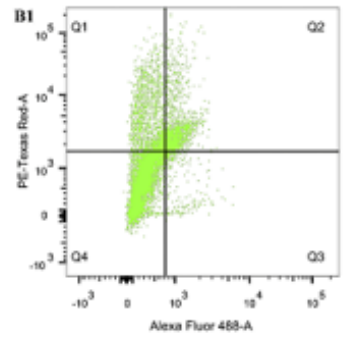

B2

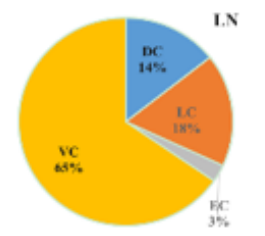

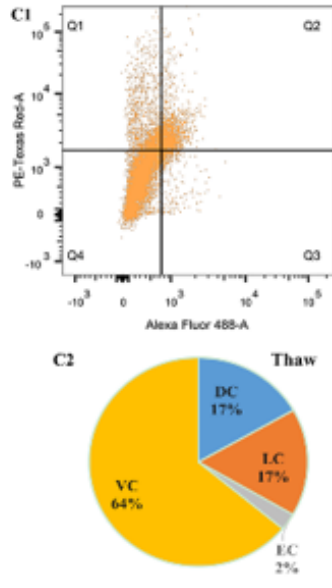

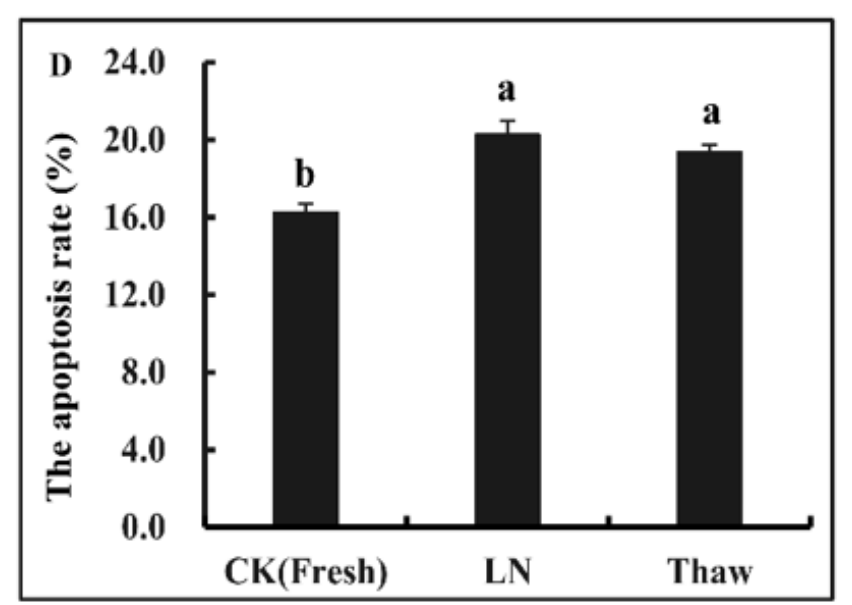

Figure 3

Changes of apoptosis rate in P. lactiflora pollen before and after cryopreservation. Notes: Values represent the mean ( \pm SE) over 3 detections. Different letters indicate significant differences among different treatments $(P<0.05)$. A: fresh pollen $(C K)$; $B$ : $L N$ preserved pollen without thaw treatment $(L N)$; $C$ : the $L N$ preserved pollen with thaw treatment (Thaw); $D$ : the changes of the total apoptosis rate before and after LN storage; 1 : the flow diagrams of Annexin V-FITC and PI double staining; 2: the proportions of death cells, living cells, and apoptotic cells of pollen. DC: the death cell; LC: the late apoptosis cell; EC: the early apoptosis cell; VC: the living cell. 

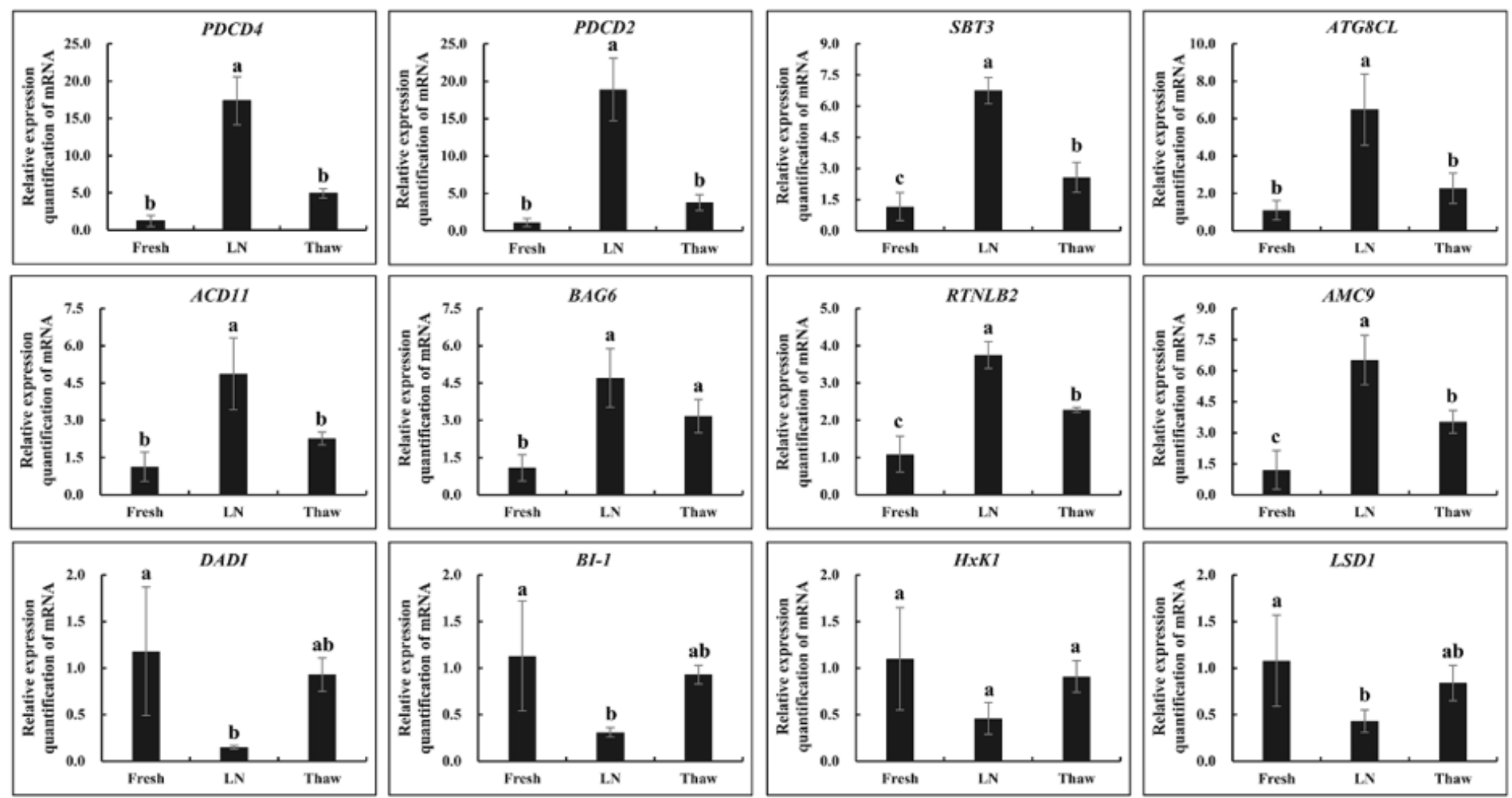

Figure 4

Changes of PCD gene in P. lactiflora pollen before and after cryopreservation. Notes: Values represent the mean $( \pm \mathrm{SE})$ over 3 detections, and different letters indicate significant differences among different treatments $(P<0.05)$. Fresh: fresh pollen $(C K) ; L N$ : $L N$ preserved pollen without thaw treatment; Thaw: the $\mathrm{LN}$ preserved pollen with thaw treatment.
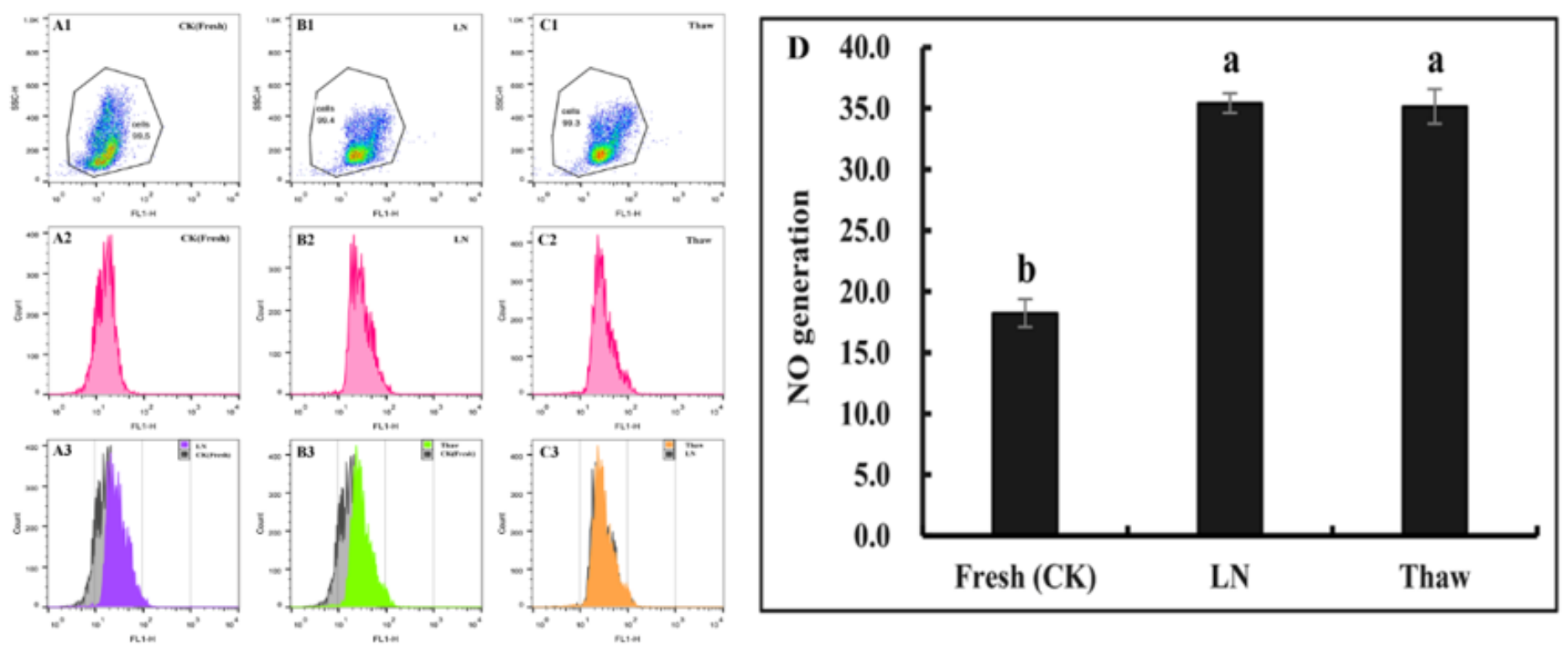

Figure 5 
Changes of NO content in P. lactiflora pollen before and after cryopreservation. Notes: Values represent the mean $( \pm \mathrm{SE})$ over 3 detections. Different letters indicate significant differences among different treatments $(P<0.05)$. A: fresh pollen $(C K) ; B$ : $L N$ preserved pollen without thaw treatment $(L N) ; C$ : the $L N$ preserved pollen with thaw treatment (Thaw); D: the NO content of pollen; 1 : the flow cytometry maps; 2 : the flow spectrogram of DAF-FM DA fluorescence (NO fluorescent probe); 3 : the comparison spectrograms.

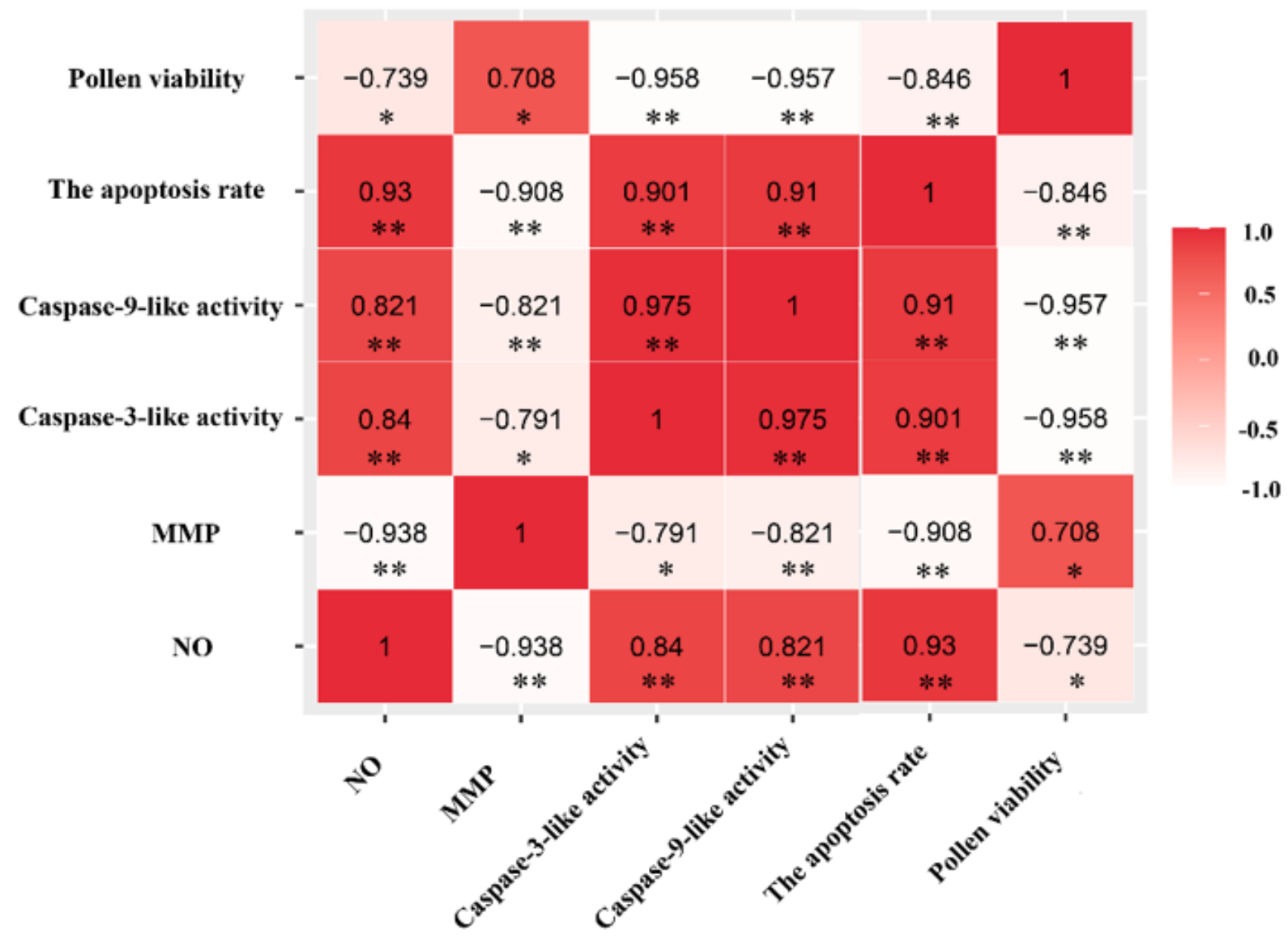

\section{Figure 6}

Correlation analysis among NO, PCD indexes and viability of P. lactiflora pollen cryopreservation. Note: Data is the correlation coefficient among different indicators. * indicates significant correlation at $\mathrm{P}<$ 0.05 , and $* *$ indicates extremely significant correlation at $P<0$. 01. NO: nitric oxide; MMP: mitochondrial membrane potential. 

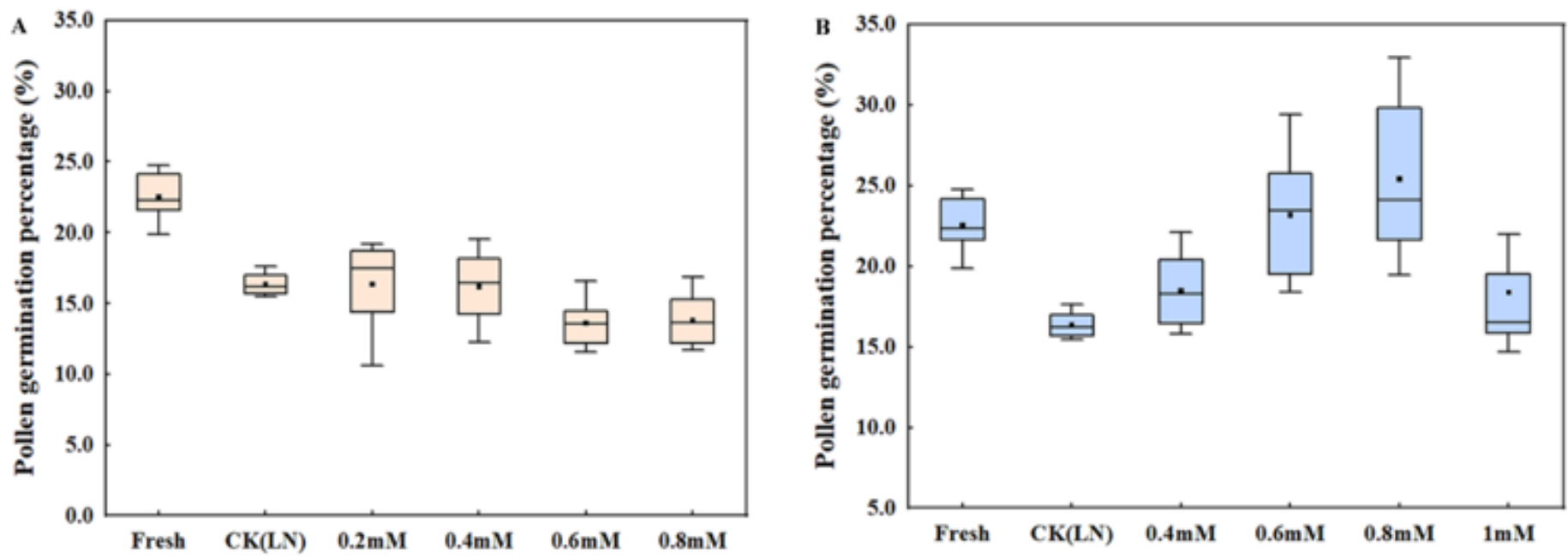

Figure 7

Changes of P. lactiflora pollen viability with and without NO regulter treatment after cryopreservation. Notes: Values represent the mean ( \pm SE) over 3 detections. A: the changes of pollen viability before and after SNP treatment; B: the changes of pollen viability before and after c-PTIO treatment.
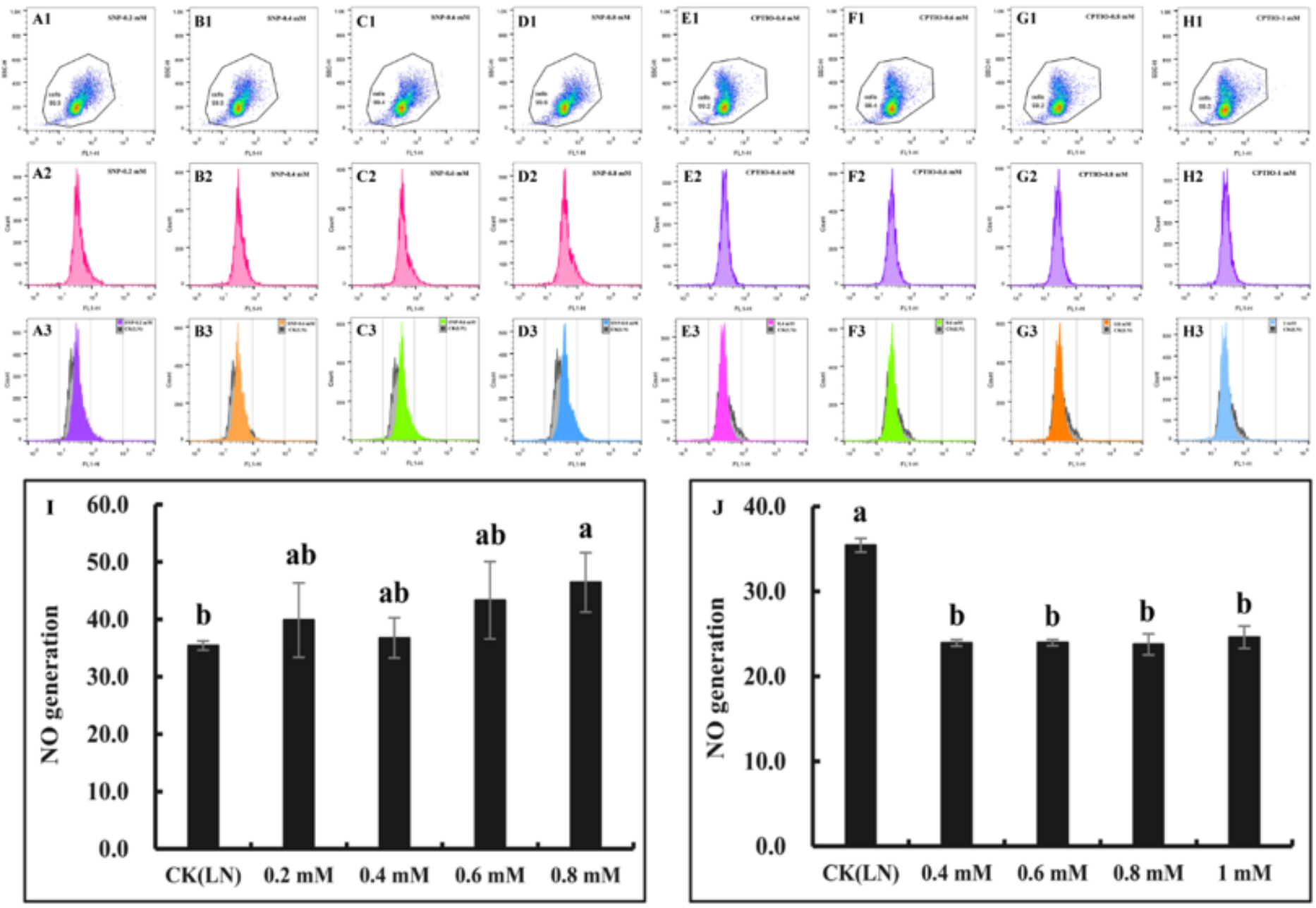

Figure 8 
Changes of endogenesis NO content in P. lactiflora pollen with and without NO regulter treatment after cryopreservation. Notes: Values represent the mean ( \pm SE) over 3 detections. Different letters indicate significant differences among different treatments at the 0.05 level $(P<0.05$, Duncan's multiple range test). A: 0.2mM SNP;B: 0.4mM SNP; C: 0.6mM SNP;D: 0.8mM SNP; E: 0.4mM c-PTIO; F: 0.6mM c-PTIO; G: $0.6 \mathrm{mM}$ c-PTIO; H: $1 \mathrm{mM}$ c-PTIO; I: the changes of endogenesis NO content before and after SNP treatment; $\mathrm{J}$ : the changes of endogenesis NO content before and after c-PTIO treatment; 1 : the flow cytometry maps; 2: the flow spectrogram of DAF-FM DA fluorescence (NO fluorescent probe); 3: the comparison spectrograms.
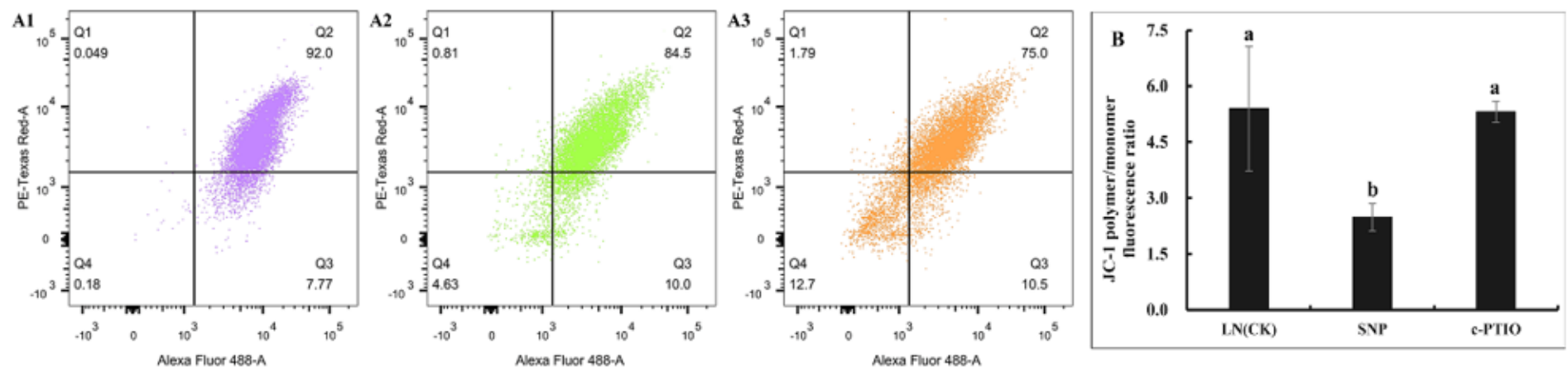

\section{Figure 9}

Changes of mitochondrial membrane potential in P. lactiflora pollen with and without NO regulter treatment after cryopreservation. Notes: Values represent the mean ( $\pm \mathrm{SE}$ ) over 3 detections. Different letters indicate significant differences among different treatments at the 0.05 level $(P<0.05$, Duncan's multiple range test). A1: LN preserved pollen (CK); A2: LN+ C-PTIO; A3: LN+SNP; B: the changes of JC-1 monomer and polymer ratio.
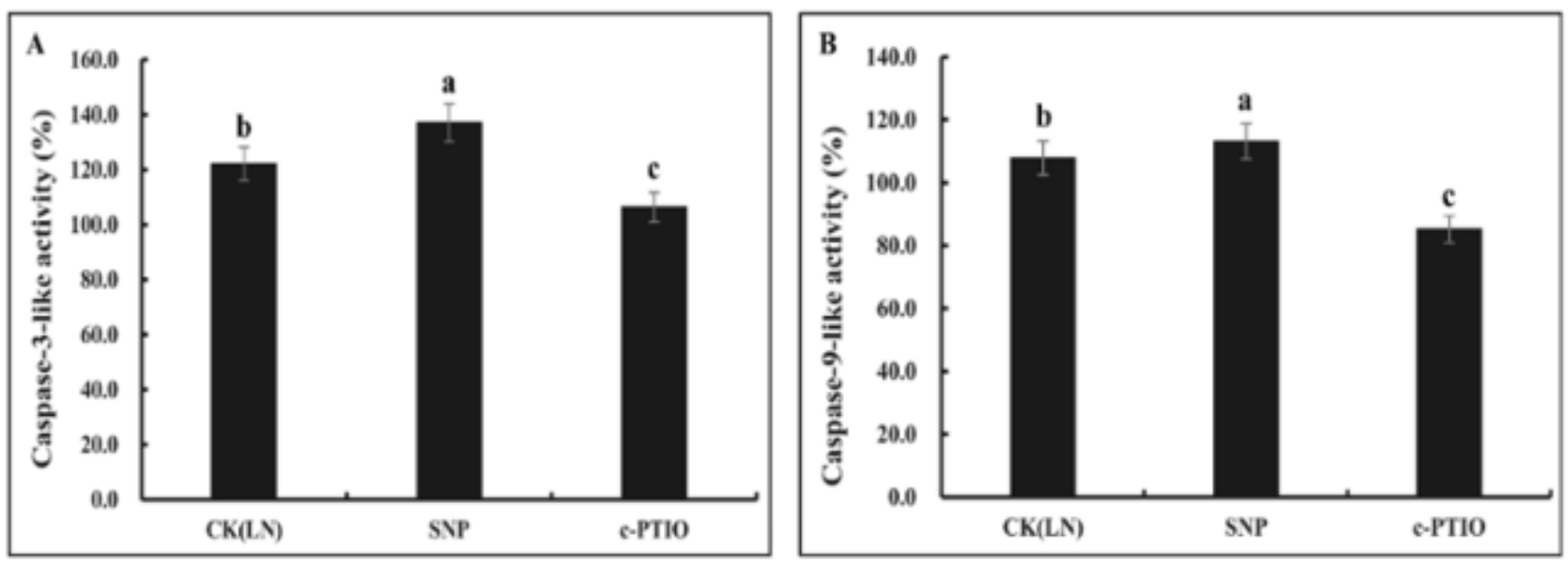

Figure 10

Changes of caspase-like protease in P. lactiflora pollen with and without NO regulter treatment after cryopreservation. Notes: Values represent the mean ( \pm SE) over 3 detections. Different letters indicate 
significant differences among different treatments at the 0.05 level $(P<0.05$, Duncan's multiple range test). A: caspase-3-like; B: caspase-9-like.

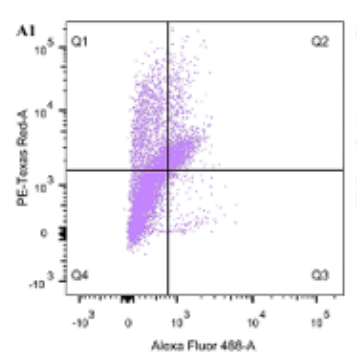

$\wedge 2$

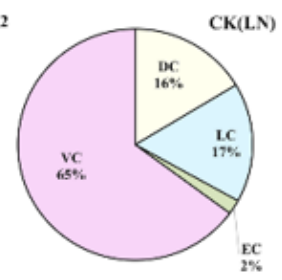

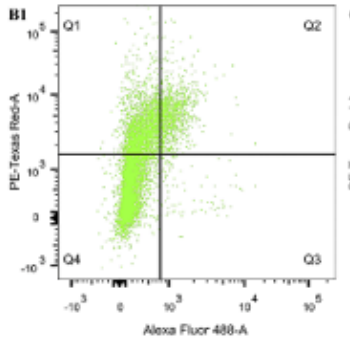

B2

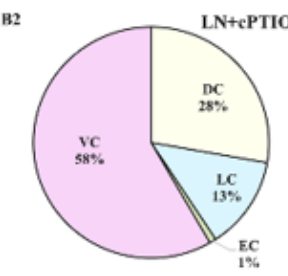

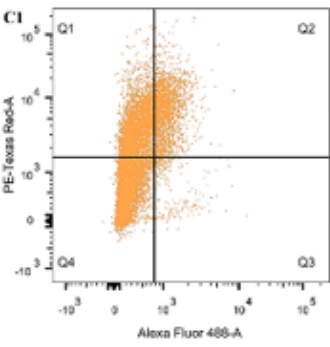

C2

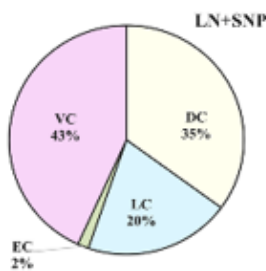

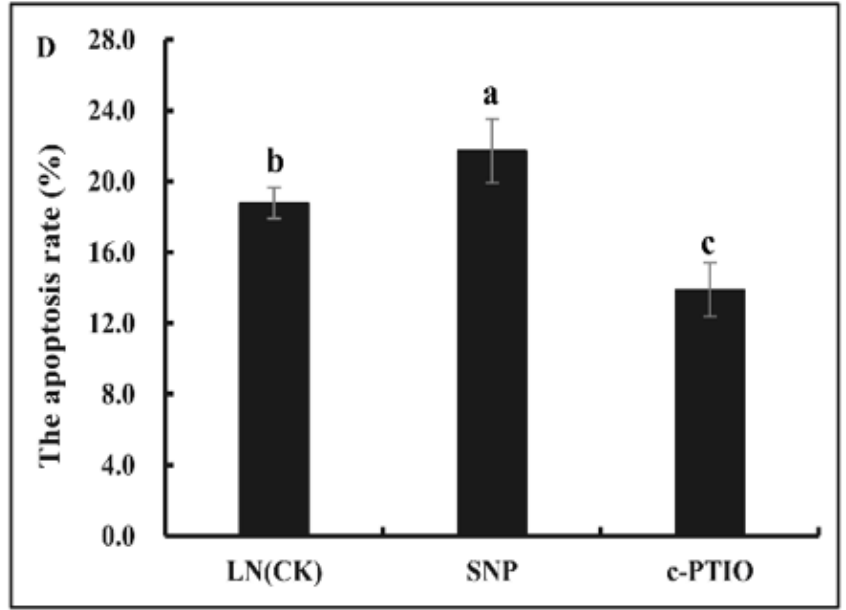

Figure 11

Changes of apoptosis rate in P. lactiflora pollen with and without NO regulter treatment after cryopreservation. Notes: Values represent the mean ( \pm SE) over 3 detections. Different letters indicate significant differences among different treatments at the 0.05 level $(P<0.05$, Duncan's multiple range test). A: LN preserved pollen (CK); B: LN+ c-PTIO; C: LN+SNP; D: the changes of the total apoptosis rate before and after LN storage; 1 : the flow diagrams of Annexin V-FITC and PI double staining; 2 : the proportions of death cells, living cells, and apoptotic cells of pollen. DC: the death cell; LC: the late apoptosis cell; EC: the early apoptosis cell; VC: the living cell. 

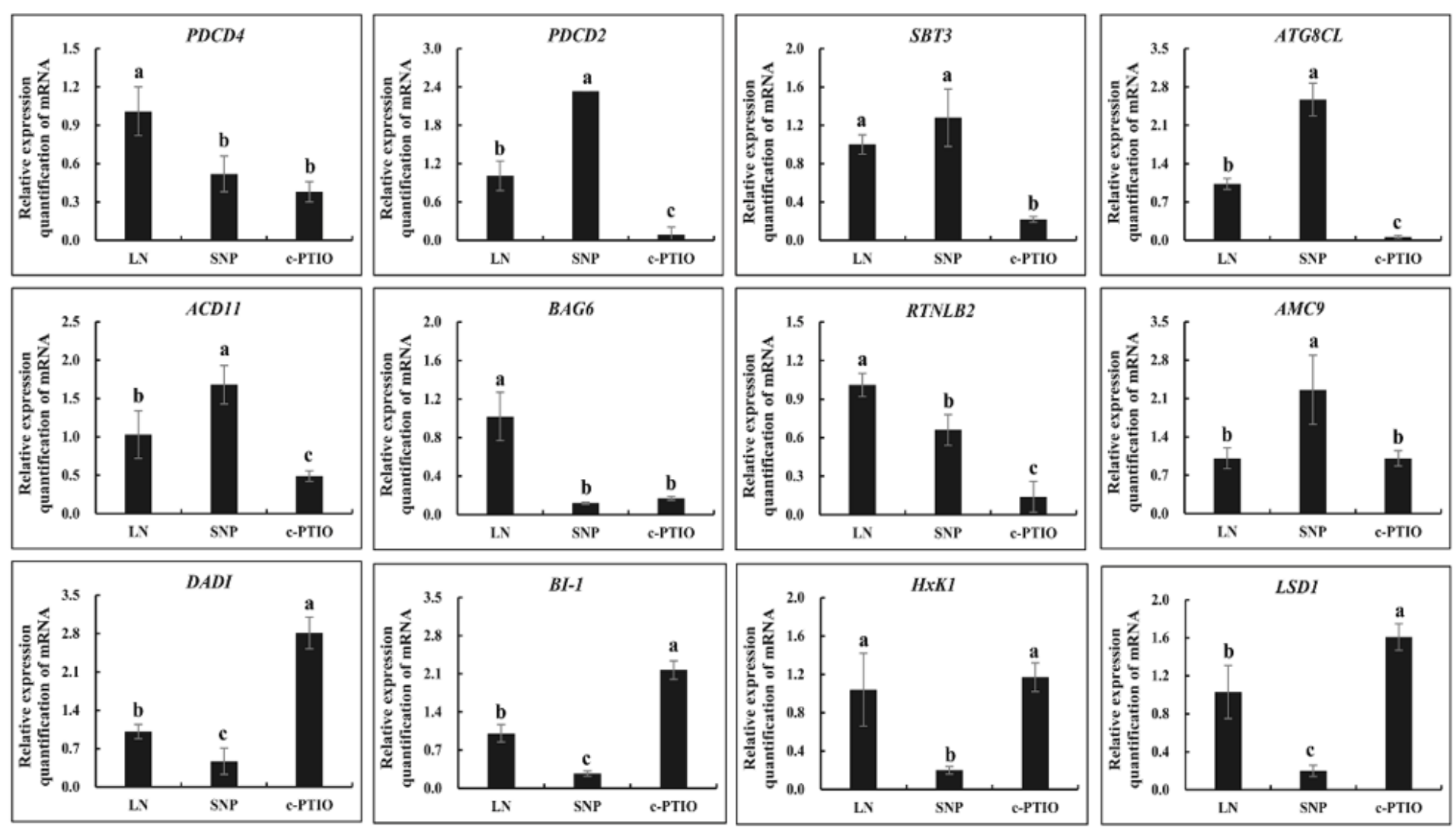

Figure 12

Changes of PCD gene in P. lactiflora pollen with and without NO regulter treatment after cryopreservation. Notes: Values represent the mean $( \pm \mathrm{SE})$ over 3 detections. Different letters indicate significant differences among different treatments at the 0.05 level ( $P<0.05$, Duncan's multiple range test). 